whether these clones give rise to contamination in the human draft sequence. As noted in the paper, we used computer programs to identify and eliminate instances of such contamination (with mouse sequence, vector sequence, and so on) before assembling the draft genome sequence. In reviewing the work, we identified one mouse clone that slipped through the filter. This clone has been eliminated in subsequent assemblies (http://genome.cse.ucsc.edu/). Because the draft sequence remains an imperfect partial product, we welcome additional comments that could help in improving it.

- The discussion of possible horizontal gene transfer from bacterial genomes to vertebrate genomes has provoked considerable discus$\operatorname{sion}^{3-5}$. We reported 113 instances of human genes that had reasonably close homologues in bacteria, but either had no homologue or only a weaker homologue in non-vertebrate eukaryotes for which extensive genomic sequence was available. We suggested two hypotheses to explain these data: horizontal gene transfer (HGT) from bacteria to human or gene loss in the other lineages. We had no data to distinguish between these hypotheses, although we suggested that the latter was a more "parsimonious" explanation as it involved fewer independent events. In the introduction we stated that this seemed "likely".

Several correspondents have undertaken more comprehensive analyses and have argued that a significant proportion of the cases can be explained by gene $\operatorname{loss}^{3-5}$. We agree. We believe that the two hypotheses cannot be distinguished on the basis of parsimony, because too little is known about the relative rates of HGT and gene loss in evolution. Instead, extensive sequence data from many additional organisms will be required to assess definitively the provenance of each gene.

We note that the process of HGT into the vertebrate genome from other organisms has clearly occurred on multiple occasions, as seen from the sudden arrival of many DNA transposons with strong similarities to other organisms. The most recent documented cases occurred subsequent to the eutherian radiation (see Fig. 19).

- A key reference concerning 3 '-transduction by LINE elements was omitted on page 887 . The sentence citing references 205 and 206 should also have cited Goodier et al. ${ }^{6}$.

- In Fig. 33, the unit on the $y$ axis should be bp, not $\mathrm{kb}$. The legend should read: "Sequence properties of segmental duplications. Distributions of length and per cent nucleotide identity are shown as a function of the number of aligned $b p$ from the finished vs finished human genomic sequence dataset. Intrachromosomal (blue), interchromosomal (red)."

- In Fig. 41, the legend should begin: "For each of the 27 common domain families, the number of different Pfam domain types that co-occur with the family in each of the five eukaryotic proteomes. The 27 families were chosen to include the 10 most common domain families in each proteome. The data are ranked ..."

- In Table 22 , the entry 81,126 should be 8,126 .

- On page 898 , line 31 , the final phrase of the sentence (" $\ldots$ and the representativeness of currently 'known' human genes") should be deleted. The sentence should read: "Before discussing the gene predictions for the human genome, it is useful to consider background issues, including previous estimates of the number of human genes and lessons learned from worms and flies".

- On page 900 , line 38 , remove "(see above)".

- We failed to acknowledge the crucial role of sequence editing software, which has been widely used for inspection and subsequent finishing of the sequence assemblies. The two principal programs used were $\mathrm{CONSED}^{7}$ and GAP4 ${ }^{8}$.

1. Burgess, D. L. et al. A cluster of three novel $(\mathrm{Ca}(2+)$ channel gamma subunit genes on chromosome 19q13.4: Evolution and expression profile of the gamma subunit gene family. Genomics 71, 339-350 (2001)

2. Aikawa, J. et al. Multiple isozymes of heparan sulfate/heparin GlcNAc N-deacetylase/GlcN Nsulfotransferase. Structure and activity of the fourth member, NDST4. J. Biol. Chem. 276, 5876-5882 (2001).

. Salzberg, S. L. et al. Microbial genes in the human genome: Lateral transfer or gene loss? Science 292, 1903-1906 (2001).
4. Stanhope, M. J. et al. Phylogenetic analyses do not support horizontal gene transfers from bacteria to vertebrates. Nature 411, 940-944 (2001).

5. Reelofs, J. \& Van Haastert, P. J. M. Genes lost during evolution. Nature 411, 1013-1014 (2001)

6. Goodier, J. L., Ostertag, E. M. \& Kazazian, H. H. Transduction of 3'-flanking sequences is common in L1 retrotransposition. Hum. Mol. Genet. 9, 653-657 (2000).

7. Gordon, D., Abajian, C. \& Green, P. Consed: a graphical tool for sequence finishing. Genome Res. 3, 195-202 (1998).

8. Staden, R., Beal, K. F. \& Bonfield, J. K. The Staden package. 1998. Methods Mol. Biol. 132, 115-130 (2000)

Supplementary information (with changes to the original Supplementary Information) is available on Nature's World-Wide Web site (http://www.nature.com).

errata

\section{The homeobox gene lim-6 is required for distinct chemosensory representations in C. elegans}

Jonathan T. Pierce-Shimomura, Serge Faumont, Michelle R. Gaston, Bret J. Pearson \& Shawn R. Lockery

Nature 410, 694-698 (2001).

In some United States issues of Nature the lines in Fig. 3a were missing or very faint. A corrected version is printed below.

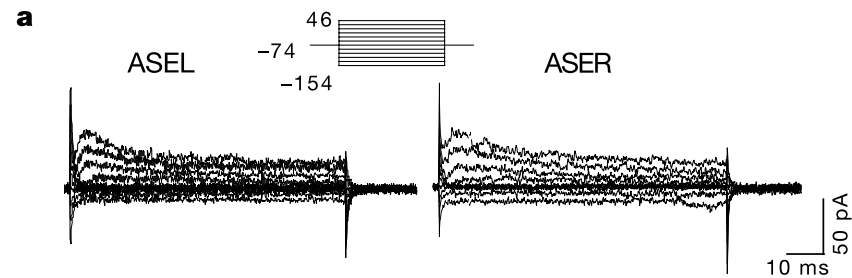

\section{The zebrafish Nodal signal Squint functions as a morphogen}

\section{Yu Chen \& Alexander F. Schier}

Nature 411, 607-610 (2001).

In Fig. 1 of this Letter, panels $\mathbf{h}, \mathbf{m}$ and $\mathbf{p}$ were incorrectly labelled. The corrected panels are reproduced below.
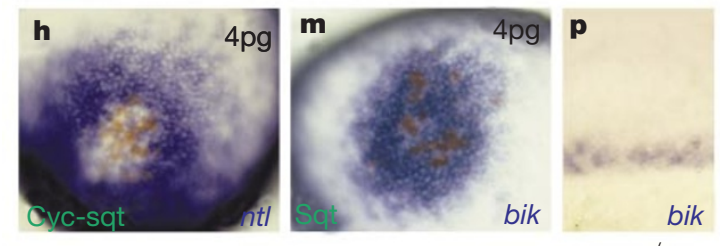

$s q t^{-1-}$ 
7. Bradshaw, M. F. \& Cumming, B. G. The direction of retinal motion facilitates binocular stereopsis. Proc. R. Soc. Lond. B 264, 1421-1427 (1997).

8. Mayhew, J. E. \& Frisby, J. P. Stereopsis masking in humans is not orientationally tuned. Perception 7, 431-436 (1978)

9. Mansfield, J. S. \& Parker, A. J. An orientation-tuned component in the contrast masking of stereopsis Vision Res. 33, 1535-1544 (1993).

10. Rogers, B. J. \& Graham, M. E. Similarities between motion parallax and stereopsis in human depth perception. Vision Res. 22, 261-270 (1982).

11. Bradshaw, M. F. \& Rogers, B. J. The interaction of binocular disparity and motion parallax in the computation of depth. Vision Res. 36, 3457-3468 (1996).

12. Tittle, J. S. \& Braunstein, M. L. Recovery of 3-D shape from binocular disparity and structure from motion. Percept. Psychophys. 54, 157-169 (1993).

13. Richards, W. Structure from stereo and motion. J. Opt. Soc. Am. A 2, 343-349 (1985).

14. Landy, M. S., Maloney, L. T., Johnston, E. B. \& Young, M. Measurement and modeling of depth cue combination: in defense of weak fusion. Vision Res. 35, 389-412 (1995).

15. Julesz, B. Foundations of Cyclopean Perception (Univ. Chicago Press, Chicago, 1971).

\section{Acknowledgements}

R.v.E. was supported by a NIH grant awarded to B.A. and by the Royal Netherlands Academy of Arts and Sciences, and B.A was supported in part by NIH.

Correspondence and requests for materials should be addressed to B.L.A (e-mail: bart@mit.edu).

\section{The homeobox gene lim- 6 is required for distinct chemosensory representations in C. elegans}

Jonathan T. Pierce-Shimomura, Serge Faumont, Michelle R. Gaston, Bret J. Pearson \& Shawn R. Lockery

Institute of Neuroscience, 1254 University of Oregon, Eugene, Oregon 97403, USA

The ability to discriminate between different chemical stimuli is crucial for food detection, spatial orientation and other adaptive behaviours in animals. In the nematode Caenorhabditis elegans, spatial orientation in gradients of soluble chemoattractants (chemotaxis) is controlled mainly by a single pair of chemosensory neurons ${ }^{1}$. These two neurons, ASEL and ASER, are left-right homologues in terms of the disposition of their somata and processes, morphology of specialized sensory endings, synaptic partners and expression profile of many genes ${ }^{2,3}$. However, recent gene-expression studies have revealed unexpected asymmetries between ASEL and ASER. ASEL expresses the putative receptor guanylyl cyclase genes $g c y-6$ and $g c y-7$, whereas ASER expresses $g c y-5$ (ref. 4). In addition, only ASEL expresses the homeobox gene lim-6, an orthologue of the human $L M X 1$ subfamily of homeobox genes $^{5}$. Here we show, using laser ablation of neurons and wholecell patch-clamp electrophysiology, that the asymmetries between ASEL and ASER extend to the functional level. ASEL is primarily sensitive to sodium, whereas ASER is primarily sensitive to chloride and potassium. Furthermore, we find that lim-6 is required for this functional asymmetry and for the ability to distinguish sodium from chloride. Thus, a homeobox gene increases the representational capacity of the nervous system by establishing asymmetric functions in a bilaterally symmetrical neuron pair.

To determine whether $C$. elegans can distinguish between the attractants sodium and chloride in our experimental system ${ }^{6}$, we performed a discrimination test in which we examined the chemotaxis performance of worms in a gradient of sodium $(50 \mu \mathrm{M}$ to $10 \mathrm{mM}$ ) superimposed on a saturating background concentration of chloride $(100 \mathrm{mM})$, and vice versa (Fig. 1a, d). In both cases, worms migrated toward the peak of the gradient as expected ${ }^{7}$, although the overall chemotaxis performance was reduced relative to control worms tested in sodium or chloride gradients but with no background ion concentration (Fig. 1b, d).

However, the chemotaxis performance of worms tested under conditions in which the gradient and background concentration contained the same ion (Fig. 1c, d) degenerated to roughly chance level, defined as the chemotaxis performance of worms tested in the absence of a gradient (Fig. 1d, dotted line). Together, these results show that sodium chemotaxis persists against a background of

$\mathrm{Cl}^{-}$gradient

$\mathrm{Na}^{+}$gradient
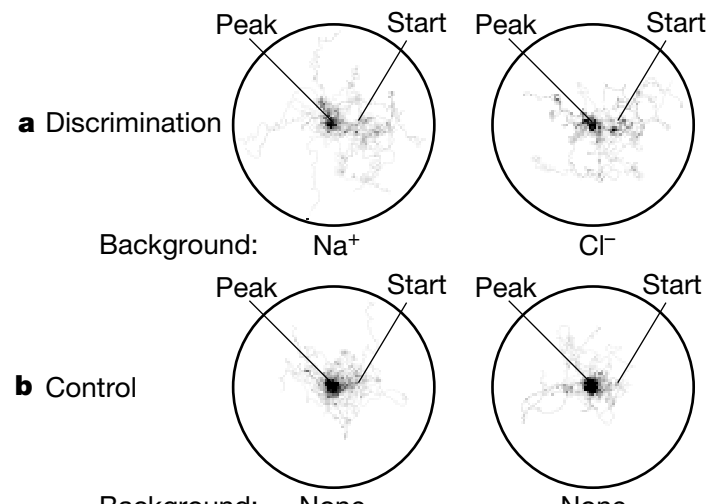

Background: None

None

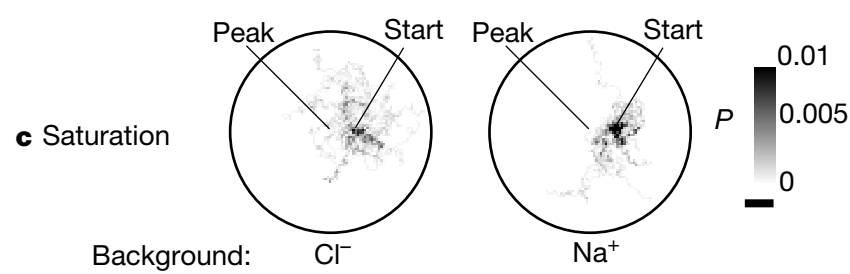

d

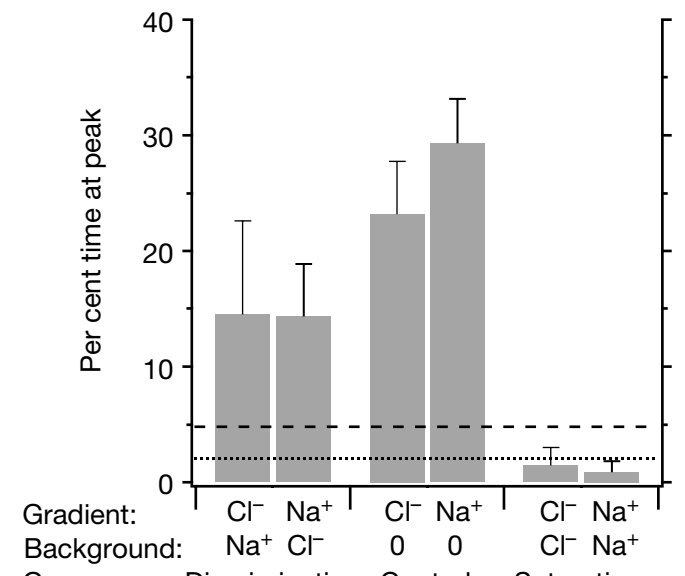

Group: Discrimination Control Saturation

Figure 1 Discrimination of sodium and chloride by wild-type C. elegans. a-c, Probability density plots for worms assayed in gradients of chloride (left) and sodium (right) originating at the centre of the plate (peak), $n \geq 15$. Grey scale indicates the probability per unit area of finding a worm at a given location in the plate during the 20-min assay. Scale bar, $1 \mathrm{~cm}$. a, Discrimination. Worms located and remained at the peak of a chloride gradient superimposed on a high background concentration (100 mM) of sodium, or at the peak of a sodium gradient superimposed on a high background concentration (100 mM) of chloride. $\mathbf{b}$, Control. Chemotaxis performance was normal in gradients identical to those in a when the background ion was omitted. c, Saturation. Worms failed to locate the peak of the gradient when it was superimposed on a high background concentration (100 $\mathrm{mM}$ ) of the same ion. $\mathbf{d}$, Average per cent time spent at the gradient peak for worms in the six conditions shown in a-c. Dotted line indicates mean chance performance, measured by assaying 74 worms in plates with neither gradient nor background. Dashed line indicates upper 95 per cent confidence limit for mean chance performance. 
chloride sufficient to saturate the chloride response, and chloride chemotaxis persists against a background of sodium sufficient to saturate the sodium response. Thus, C. elegans has distinct sensory pathways for detecting sodium and chloride ions, in agreement with previous qualitative observations ${ }^{7}$.

To identify the neuronal constituents of these two sensory pathways, we compared the effects on chloride and sodium chemotaxis of unilateral ablations of the ASE neurons (Fig. 2a, b). We found that chloride chemotaxis was disrupted by ablation of ASER, indicating that it is a necessary constituent of the chloride sensory pathway. In contrast, chloride chemotaxis was unaffected by ablation of ASEL, suggesting that ASEL is not a necessary constituent of the chloride pathway. Furthermore, we found that sodium chemotaxis was disrupted by ablation of ASEL, indicating that it is a necessary constituent of the sodium sensory pathway. Although ablation of ASER had little or no effect on sodium chemotaxis, the effect of bilateral ablation of the ASE neurons was greater than the effect of unilateral ablation of ASEL (Bonferroni post hoc comparison, $P<0.001)$. Thus, ASER seems to be a secondary constituent of the sodium pathway. We conclude that the asymmetries in gene expression in the ASE neurons coincide with differences in sensory function.

As the strongest unilateral ablation effects were for ASEL in the case of sodium chemotaxis and ASER in the case of chloride chemotaxis, we thought that ASEL and ASER might be specialized for detection of cations and anions, respectively. Therefore, we compared the effects of unilateral and bilateral ablation of ASE neurons on potassium chemotaxis as an example of a response to a second cation (Fig. 2c). We found that potassium chemotaxis was disrupted by ablation of ASER, but not by ablation of ASEL, indicating that ASER is a necessary constituent of the potassium pathway, but ASEL is not. Thus, ASER is not specialized for detecting anions, and the functional asymmetries between ASEL and ASER extend to a third ion.
The ablation data are summarized in Fig. 2d, which shows the respective contribution of the ASE neurons to the sodium, chloride and potassium pathways. (The three other chemosensory neuron pairs known to be necessary for normal chemotaxis to sodium and chloride ions - ADF, ASG and ASI - were not tested because their joint contribution to chemotaxis is much less than that of the ASE neurons ${ }^{1}$.) Only ASER contributes to the chloride and potassium pathways. Both ASER and ASEL contribute to the sodium pathway, but the latter makes the stronger contribution.

Our finding that ASEL, the main constituent of the sodium pathway, is not part of the potassium pathway suggests that sodium chemotaxis should persist against a high background of potassium - a prediction at odds with previous work ${ }^{7}$. In our more quantitative behavioural assay, however, sodium chemotaxis persists against a background of $100 \mathrm{mM}$ potassium (per cent time at peak: $\mathrm{Na}^{+}$gradient with $\mathrm{K}^{+}$background, $20.7 \pm 6.02, n=18$, versus no gradient, $1.97 \pm 1.02, n=74 ; t=6.02, P<0.0001)$. We did, however, observe a substantial reduction in potassium chemotaxis against a background of $100 \mathrm{mM}$ sodium (per cent time at peak: $\mathrm{K}^{+}$gradient with $\mathrm{Na}^{+}$background, $8.37 \pm 5.35, n=33 ; \mathrm{K}^{+}$gradient with no background, 23.1 $\pm 5.67, n=15 ; t=3.91, P<0.001$ ), consistent with previous results ${ }^{7}$ and our finding that the potassium pathway and the secondary sodium pathway converge on ASER.

To determine whether the differences between ASEL and ASER in sensory function are reflected in their electrophysiology, we performed whole-cell voltage-clamp recordings from ASEL for comparison with previous recordings from $\mathrm{ASER}^{8}$. Net membrane current evoked by a family of voltage pulses between -154 and $+46 \mathrm{mV}$ (holding potential $=-74 \mathrm{mV}$ ) was qualitatively similar in ASEL and ASER (Fig. 3a). Both neurons exhibited a timeindependent inward current activated by hyperpolarization below $-90 \mathrm{mV}$, and a fast activating outward current activated by depolarization. Outward current decayed exponentially over time in both neurons.

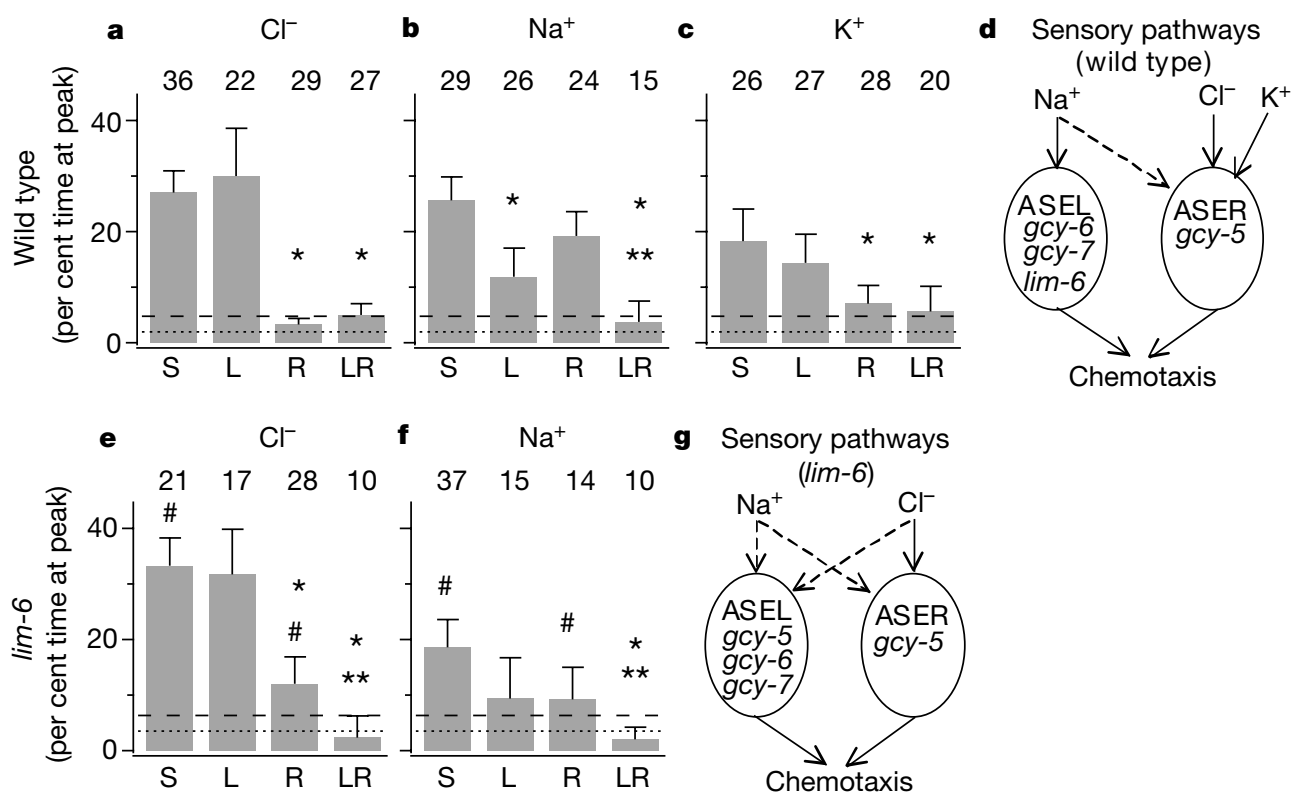

Figure 2 Effect of ablations of ASEL and ASER on chemotaxis performance in chloride, sodium and potassium gradients. a-c, e, f, Per cent time at the gradient peak for four groups of worms: unablated sham (S), ASEL ablation (L), ASER ablation (R), and ASEL plus ASER ablation (LR). Single asterisks indicate a significant difference relative to sham $(P<0.01)$; double asterisks indicate a significant difference relative to the ASEL ablation or the ASER ablation $(P<0.01)$; hash indicates a significant difference relative to the same groups in wild-type worms $(P<0.05)$. Numbers above the bars indicate sample sizes. Dotted lines indicate mean chance performance, measured by assaying worms in plates with neither gradient nor background. Dashed lines indicate the upper 95 per cent confidence limit for chance performance. $\mathbf{d}$, Summary of the sodium, chloride, and potassium sensory pathways based on the data in $\mathbf{a}-\mathbf{c}$. Dashed line indicates that ASER is a secondary constituent of the sodium pathway. $\mathbf{g}$. Summary of the sodium and chloride sensory pathways in lim- 6 based on the data in $\mathbf{e}$ and $\mathbf{f}$; the potassium pathway was not tested. Dashed lines indicate weakened or secondary sensory function. The asymmetric function of the ASE neurons is correlated with asymmetric expression of the receptor guanylyl cyclase genes gcy-5, -6 and -7 and the homeobox gene lim- 6 (refs 4,5 ). 
Substitution of $N$-methyl-D-glucamine for potassium in the recording pipette abolished outward current in both ASEL (data not shown) and $\mathrm{ASER}^{8}$, suggesting that it is carried by potassium ions. Rates of inactivation for outward current vary widely among C. elegans neurons ${ }^{8}$. We therefore compared inactivation rates of the outward current at $+46 \mathrm{mV}$ for ASER and ASEL. Notably, we found no statistical difference in the time constants of inactivation for ASER $(19.7 \pm 2.4 \mathrm{~ms} ; n=31)$ and ASEL $(20.8 \pm 3.9 \mathrm{~ms} ; n=12$, $t=1.60, P>0.05)$, suggesting that the transient current may be carried by the same or similar potassium channels.

Plots of peak current density versus voltage were also strikingly similar for ASEL $(n=14)$ and ASER $(n=29)$ (Fig. 3b, left). The plot of steady-state current density versus voltage, however, revealed that outward current density above $-14 \mathrm{mV}$ is increased about 1.52 -fold in ASEL (Fig. 3b, right; analysis of variance, $P<0.01$ ). Thus, the difference in sensory function between ASEL and ASER is reflected in a difference in the amount of outward current generated when the neuron is depolarized, which could in turn produce a difference in the threshold for regenerative events seen in ASE neurons ${ }^{8}$. Whereas the functional consequence of this difference remains to be investigated, the overall electrophysiological similarity of the two neurons suggests that differences in the chemosensitivies of the two neurons to sodium, chloride and potassium, rather than differences in voltage-dependent currents, are responsible for the asymmetrical contributions of ASEL and ASER to chemotaxis.

In the mutant lim-6(nr2073), a putative null missing the homeodomain and one of two LIM domains of the protein, $g c y-5$, which is normally expressed only in ASER, is also expressed in ASEL ${ }^{5}$. Thus, the lim-6 gene is required for asymmetric $g c y$-5 expression in ASEL and ASER. To determine whether the $\mathrm{lim}-6$ gene is also required for the asymmetric sensory functions of ASEL and ASER, we compared the effect on chloride chemotaxis of unilateral ablations of ASE neurons in lim-6 mutants (Fig. 2e). We found that although chloride chemotaxis was reduced by ablation of ASER, the reduction was significantly less than in wild-type worms (Fig. 2e, R, versus Fig. 2a, R: $t=3.72, P<0.001)$. Moreover, lim-6 mutants in which ASER was ablated performed significantly better than chance (Fig. 2e, $\mathrm{R}$, versus chance: $t=3.17, P<0.01$ ), in contrast to wild-type worms in which ASER was ablated (Fig. 2a, $R$, versus chance: $t=0.867, P>0.05)$. Thus, in lim-6 mutants, chloride a

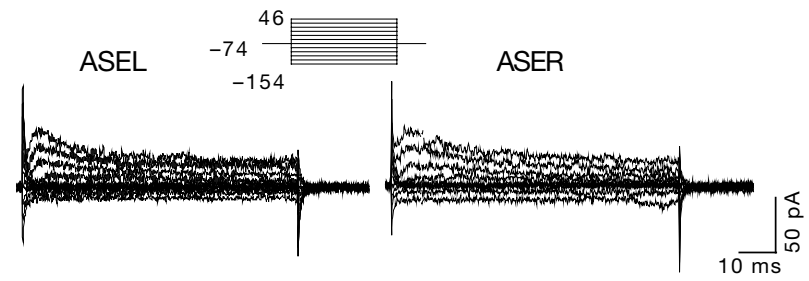

b Peak current
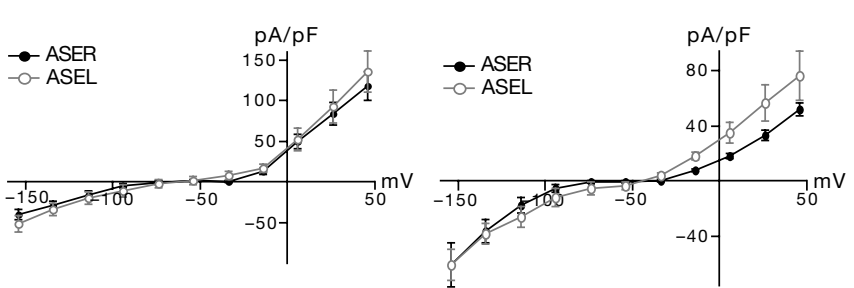

Figure 3 Comparison of membrane currents in ASEL and ASER. a, Currents evoked by a family of 80 -ms voltage pulses between -154 and $+46 \mathrm{mV}$ from a holding potential of $-74 \mathrm{mV}$ in ASEL (left) and ASER (right). b. Current density versus voltage plots for peak (left) and steady-state current (right) in ASER (filled circles, $n=29$ ) and ASEL (open circles, $n=14$ ). Steady-state current was calculated as the mean current over the last five milliseconds of the voltage pulse. Bars, 95 per cent confidence intervals. chemotaxis persists in the absence of ASER, suggesting the existence of a new constituent of the chloride pathway.

A likely candidate for this constituent was ASEL, because it now expressed $g c y-5$, a characteristic feature of the chloride-sensitive ASER neuron. Although killing ASEL had no effect on chloride chemotaxis in lim-6 mutants, killing ASER together with ASEL reduced chloride chemotaxis more than ablating ASER alone

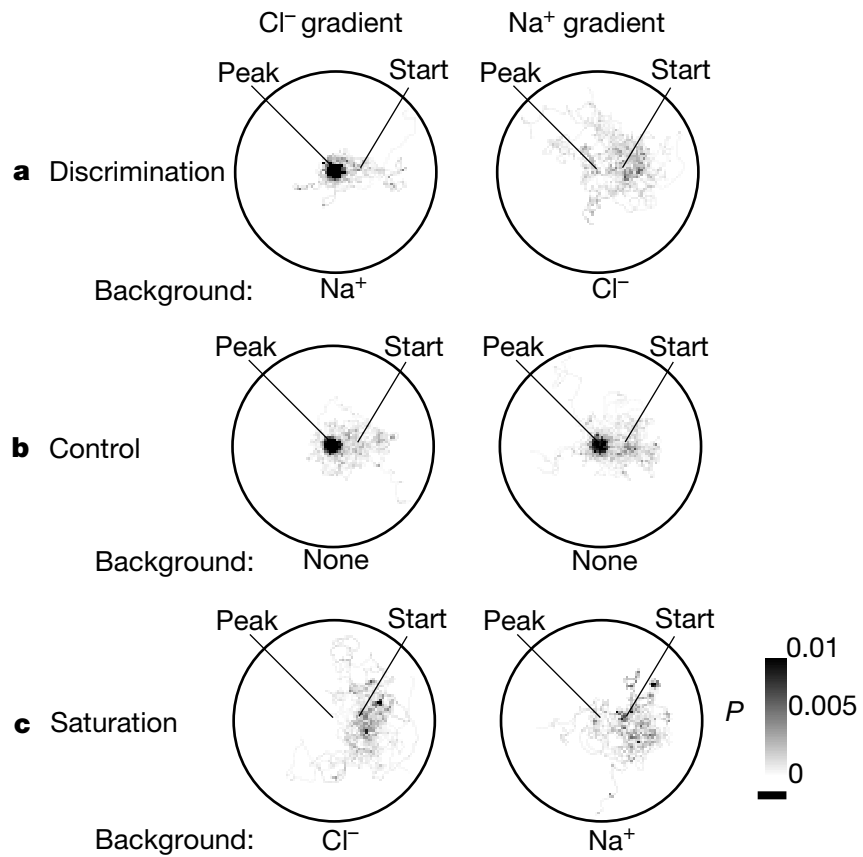

d

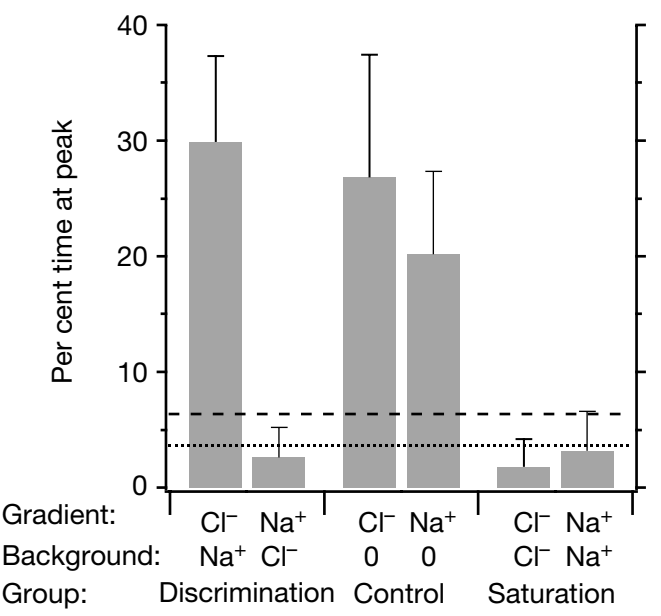

Figure 4 Discrimination of sodium and chloride in lim- 6 mutants. a-c, Probability density plots for lim- 6 mutants assayed in gradients of chloride (left) and sodium (right) originating at the centre of the plate (peak) $(n \geq 15)$. Grey scale indicates the probability per unit area of finding a worm at a given location in the plate during the 20-min assay. Scale bar, $1 \mathrm{~cm}$. a, Discrimination. lim- 6 mutants located and remained at the peak of a chloride gradient superimposed on a high background concentration (100 mM) of sodium (left) but failed to locate the peak of a sodium gradient superimposed on a high background concentration (100 mM) of chloride (right). b. Control. lim- 6 mutants located and remained at the peak of gradients identical to those in a when the background was omitted. c, Saturation. lim- 6 mutants failed to locate the peak of the gradient when it was superimposed on a high background concentration $(100 \mathrm{mM})$ of the same ion. $\mathbf{d}$, Average per cent time spent at the gradient peak for worms in the six conditions shown in a-c. Dotted line indicates mean chance performance, measured by assaying 36 mutants in plates with neither gradient nor background. Dashed line indicates the upper 95 per cent confidence interval for chance performance. 
(Bonferroni post hoc comparison, $P<0.001$ ), with chloride chemotaxis reduced to the chance level. These results suggest that in lim-6 mutants ASEL is responsible, at least in part, for the persistence of chloride chemotaxis in the absence of ASER. We conclude that the lim- 6 gene is required to separate fully the sensory functions of ASEL and ASER.

The abnormal sensitivity of ASEL to chloride in lim- 6 mutants raised the possibility that the sodium pathway was altered in these worms. Indeed, we found that sodium chemotaxis was reduced in lim-6 mutants relative to wild-type worms (Fig. 2f, S, versus Fig. 2b, S: $t=2.12, P<0.05)$. This reduction appears to reflect an impairment of chemotaxis ability specific to sodium because chloride chemotaxis was actually enhanced in $\mathrm{lim}-6$ mutants relative to wildtype worms (Fig. 2e, S, versus Fig. $2 \mathrm{a}, \mathrm{S}: t=2.02, P<0.05$ ). In contrast to unilateral ablations of the ASE neurons in wild-type animals (Fig. 2b, L and R), ablation of ASEL or ASER in lim-6 mutants produced equivalent modest, yet not significant, reductions in chemotaxis to sodium (Fig. $2 \mathrm{f}, \mathrm{L}$ and $\mathrm{R}$ ). This result suggests that in lim-6 mutants, ASEL and ASER may have identical functions in the weakened sodium pathway. Bilateral ablation of the ASE neurons resulted in a significant reduction in sodium chemotaxis (Fig. 2f, S, versus Fig. 2f, LR: Bonferroni post hoc comparison, $P<0.01$ ), indicating that ASEL and ASER remain constituents of the sodium pathway in the lim-6 mutant. We conclude that although the constituents of the sodium pathway were not changed in lim-6 mutants, the lim- 6 gene is required to establish the full sensitivity to sodium of ASEL. The ablation data for lim- 6 mutants are summarized in Fig. $2 \mathrm{~g}$, in which a strengthened chloride pathway relies on both ASEL and ASER, and a weakened sodium pathway also relies on both ASEL and ASER.

Previous experiments have shown that the G-protein-coupled receptor STR-2 is expressed in either the left or the right member of the chemosensory neuron pair $\mathrm{AWC}^{9}$, and that this asymmetry is necessary for behavioural discrimination in olfactory chemotaxis (P. D. Wes and C. I. Bargmann, personal communication). The fact that the lim- 6 gene is required for asymmetric expression of $g c y-5$ suggests that lim-6 may similarly be required for the behavioural discrimination between sodium and chloride ions. To test this idea, we performed a discrimination test on lim-6 mutants under conditions identical to those in Fig. 1. We found that lim-6 mutants could perform chemotaxis to chloride in a sodium background (Fig. 4a, d), indicating that the lim-6 gene is not required for behavioural discrimination of chloride from sodium. In contrast, we found that lim-6 mutants could not perform chemotaxis to sodium in a chloride background (Fig. 4a, d). Note that this effect cannot be explained by a loss of sodium sensitivity because lim-6 mutants could perform chemotaxis to an identical sodium gradient with no background ion (Fig. 4b, d), albeit at a slightly reduced level compared with wild-type worms (Fig. 1b, d; $t=2.12, P<0.05)$. Thus, the homeobox gene lim-6 is required to discriminate sodium from chloride.

With just eight left-right homologous pairs of chemosensory neurons $s^{1,10-12}$ known to direct behavioural responses to at least 100 water soluble attractants and repellents ${ }^{7,13}, C$. elegans faces a significant limitation in its ability to differentiate chemical stimuli. Our finding of functional asymmetries between the ASE neurons suggests that $C$. elegans has adopted the unexpected solution of increasing the effective number of different types of chemosensory neurons by breaking bilateral symmetry. Similarly, only three pairs of chemosensory neurons are known to direct responses to at least 60 volatile attractants and repellents in C. elegans ${ }^{14}$, and functional asymmetries have been described in one of these neuron pairs as well ${ }^{15}$. An analogous limitation may exist in the mammalian olfactory system in which hundreds of thousands of different chemical stimuli are discriminated by just 2,000 glomeruli ${ }^{16}$ - the main functional units of the olfactory bulb. By analogy to $C$. elegans chemosensation, discrimination in mammalian olfaction could be enhanced by breaking bilateral symmetry in the activation of glomeruli ${ }^{17}$.

\section{Methods}

\section{Chemotaxis assays}

Single adult hermaphrodites were rinsed to remove OP50 bacteria and placed on a foodless, agar-filled plate for 10-40 min to accommodate, before being transferred to a second agar-filled plate in which a radially shaped gradient of attractant was established. The agar contained (in mM): $\mathrm{CaCl}_{2}(1), \mathrm{MgSO}_{4}$ (1) and $\mathrm{KPO}_{4}$ (25); $\mathrm{pH}$ 6.5. A gradient of either ammonium chloride, sodium acetate or potassium acetate was established by placing a $5-\mu \mathrm{l}$ drop of $1 \mathrm{M}$ attractant in the centre of the assay plate at $18-24 \mathrm{~h}$, and again at 3-4 h before each assay ${ }^{7}$. The maximum estimated attractant concentration ${ }^{6}$ was $\sim 10 \mathrm{mM}$ at the centre of the assay plate, and the minimum concentration was $\sim 50 \mu \mathrm{M}$ at the edge of the plate. At these concentrations, neither ammonium nor acetate ions are attractive $\mathrm{e}^{7}$. We recorded movement by noting the location of the worm's centroid at 1-s intervals for 20 min using an automated tracking system with 257 pixels $\mathrm{mm}^{-1}$ resolution ${ }^{6}$. Each animal started $11 \mathrm{~mm}$ away from the gradient peak, and was tested only once.

\section{Laser ablation of neurons}

Neurons were ablated in L1 and early L2 larvae as described ${ }^{18}$. Neurons were identified for ablation by expression of green fluorescent protein (GFP) restricted to ASER by the $g c y-5$ promoter, and restricted to ASEL by the $g c y-6$ promotor ${ }^{4}$. The presence of GFP did not affect chemotaxis, because performance was identical for animals with and without GFP expression in ASE neurons (per cent time at peak: animals with GFP, 27.1 $\pm 3.67, n=38$, versus animals without GFP, $23.15 \pm 4.55, n=17 ; t=1.31, P>0.05$ ). Ablated animals were tested for chemotaxis 2-4 d after ablation; individuals in which GFP was still visible in the target neuron after ablation were excluded from the behavioural analysis. In sham ablations, the laser was fired near the worm without killing any cells. We took two additional measures to control for nonspecific effects. First, worms in which ASE neurons were ablated were tested for chemotaxis to diacetyl, a compound sensed by a different chemosensory neuron pair, AWA ${ }^{14,19}$. Diacetyl gradients were made by placing a $1-\mu l$ drop of diacetyl (aqueous dilution 1:100) on the assay plate $\sim 10 \mathrm{~min}$ before the start of each experiment. In agreement with previous results ${ }^{14}$, animals with unilateral and bilateral ablations of ASE neurons exhibited normal diacetyl chemotaxis (per cent time at peak: sham, 21.7 $\pm 6.16, n=15$; ASEL ablated, $22.5 \pm 10.0, n=9$; ASER ablated, $20.7 \pm 7.44$, $n=12$; both ASEL and ASER ablated, 24.6 $\pm 5.23, n=10 ; F=0.161, P>0.05$ ). Second, we found no difference in average instantaneous speed (used as a measure of vitality) between worms in which ASE neurons were ablated and shams (speed: ablated, $136 \pm 5.13 \mu \mathrm{m} \mathrm{s}^{-1}, n=308$, versus sham, $145 \pm 7.89 \mu \mathrm{m} \mathrm{s}^{-1}, n=149 ; t=1.65, P>$ $0.05)$.

\section{Electrophysiology}

Animals were prepared and dissected as described ${ }^{8,20}$. We carried out whole-cell patchclamp recordings using electrodes made from borosilicate glass tubing (Sutter BF120-69 10 , Novato, CA) filled with (in $\mathrm{mM}$ ): potassium gluconate (125), $\mathrm{KCl}(18), 4 \mathrm{NaCl}(4)$, $\mathrm{MgCl}_{2}$ (1), $\mathrm{CaCl}_{2}$ (0.6), HEPES (10), EGTA (10); $\mathrm{pH} 7.2$ with KOH. In some experiment $\mathrm{N}$-methyl-D-glucamine was substituted for $\mathrm{K}^{+}$in the recording pipette. External saline contained (in mM): $\mathrm{NaCl}$ (145), $\mathrm{KCl}$ (5), $\mathrm{CaCl}_{2}$ (1), $\mathrm{MgCl}_{2}$ (5), HEPES (10), D-glucose (20); pH 7.2 with $\mathrm{NaOH}$. Membrane current was amplified with a modified Axopatch $200 \mathrm{~A}$ (Axon Instruments, Foster City, CA), filtered at $10 \mathrm{kHz}$ and digitized at $25 \mathrm{kHz}$. Voltages were corrected for liquid junction potentials. Neurons were identified by GFP expression as described above.

\section{Data analysis}

Probability density plots were made by counting the total number of visits made by a given test group to each square millimetre of the assay plate and dividing by the total number of sample intervals. Instantaneous speed was calculated by measuring the displacement of the centroid of the worm once per second. We quantified chemotaxis performance by computing the percentage of time that the centroid of the animal was within a circular region (10-mm diameter) centred at the peak of the gradient. The results presented here remained qualitatively the same when the diameter of the peak region used to calculate chemotaxis performance was increased to $20 \mathrm{~mm}$ (data not shown). All averages are reported \pm 95 per cent confidence intervals.

Received 7 November 2000; accepted 25 January 2001

1. Bargmann, C. I. \& Horvitz, H. R. Chemosensory neurons with overlapping functions direct chemotaxis to multiple chemicals in C. elegans. Neuron 7, 729-742 (1991).

2. Ward, S., Thompson, N., White, J. \& Brenner, S. Electron microscopical reconstruction of the anterior sensory anatomy of the nematode Caenorhabditis elegans. J. Comp. Neurol. 160, 313-338 (1975).

3. White, J., Southgate, E., Thompson, J. \& Brenner, S. The structure of the nervous system of the nematode Caenorhabditis elegans. Phil. Trans. R. Soc. Lond. B 314, 1-340 (1986).

4. Yu, S., Avery, L., Baude, E. \& Garbers, D. L. Guanylyl cyclase expression in specific sensory neurons: a new family of chemosensory receptors. Proc. Natl Acad. Sci. USA 94, 3384-3387 (1997).

5. Hobert, O., Tessmar, K. \& Ruvkun, G. The Caenorhabditis elegans lim-6 LIM homeobox gene regulates neurite outgrowth and function of particular GABAergic neurons. Development 126, 1547-1562 (1999).

6. Pierce-Shimomura, J. T., Morse, T. M. \& Lockery, S. R. The fundamental role of pirouettes in Caenorhabditis elegans chemotaxis. J. Neurosci. 19, 9557-9569 (1999).

7. Ward, S. Chemotaxis by the nematode Caenorhabditis elegans: identification of attractants and analysis of the response by use of mutants. Proc. Natl Acad. Sci. USA 70, 817-821 (1973). 
8. Goodman, M. B., Hall, D. H., Avery, L. \& Lockery, S. R. Active currents regulate sensitivity and dynamic range in C. elegans neurons. Neuron 20, 763-772 (1998).

9. Troemel, E. R., Sagasti, A. \& Bargmann, C. I. Lateral signaling mediated by axon contact and calcium entry regulates asymmetric odorant receptor expression in C. elegans. Cell 99, 387-398 (1999).

10. Bargmann, C. I., Thomas, J. H. \& Horvitz, H. R. Chemosensory cell function in the behavior and development of Caenorhabditis elegans. Cold Spring Harb. Symp. Quant. Biol. 55, 529-538 (1990).

11. Bargmann, C. I. \& Horvitz, H. R. Control of larval development by chemosensory neurons in Caenorhabditis elegans. Science 251, 1243-1246 (1991).

12. Kaplan, J. M. \& Horvitz, H. R. A dual mechanosensory and chemosensory neuron in Caenorhabditis elegans. Proc. Natl Acad. Sci. USA 90, 2227-2231 (1993).

13. Dusenbery, D. B. Analysis of chemotaxis in the nematode by counter current separation. J. Exp. Zool. 188, 41-47 (1974)

14. Bargmann, C. I., Hartwieg, E. \& Horvitz, H. R. Odorant-selective genes and neurons mediate olfaction in C. elegans. Cell 74, 515-527 (1993).

15. Wes, P. D. \& Bargmann, C. I. C. elegans odour discrimination requires asymmetric diversity in olfactory neurons. Nature 410, 698-701 (2001).

16. Mori, K. \& Yoshihara, Y. Molecular recognition and olfactory processing in the mammalian olfactory system. Prog. Neurobiol. 45, 585-619 (1995).

17. Rubin, B. D. \& Katz, L. C. Optical imaging of odorant representations in the mammalian olfactory bulb. Neuron 23, 499-511 (1991)

18. Bargmann, C. I. \& Avery, L. Laser killing of cells in Caenorhabditis elegans. Methods Cell Biol. 48, 225 250 (1995).

19. Sengupta, P., Chou, J. H. \& Bargmann, C. I. odr-10 encodes a seven transmembrane domain olfactory receptor required for responses to the odorant diacetyl. Cell 84, 899-909 (1996).

20. Lockery, S. R. \& Goodman, M. B. Tight-seal whole-cell patch clamping of C. elegans neurons. Methods Enzymol. 295, 201-217 (1998).

\section{Acknowledgements}

We thank C. Bargmann and P. Wes for discussions and sharing unpublished data; O. Hobert for suggesting study of the lim- 6 mutant; J. H. Thomas for technical instruction O. Hobert, D. Garbers and The C. elegans Genetics Center for strains; M. Moravec and J. Cervantes for technical assistance; and J. Eisen, M. Goodman, T. Morse and M. Westerfield for discussion. This work was supported by the National Science Foundation; the National Institute of Mental Health; the National Heart, Lung, and Blood Institute; the Office of Naval Research; The Sloan Foundation; and The Searle Scholars Program.

Correspondence and requests for materials should be addressed to S.R.L (e-mail: shawn@lox.uoregon.edu). into distinct olfactory neurons or into unique combinations of olfactory neurons.

Caenorhabditis elegans, like other animals, detects odours with G-protein-coupled receptors such as the high-affinity diacetyl receptor encoded by the odr-10 gene ${ }^{3}$. Individual chemosensory neurons express several receptor genes ${ }^{4,5}$, potentially allowing them to detect many odours but presenting a challenge for discriminating among odours. Nevertheless, C. elegans does exhibit the ability to distinguish between many odours in behavioural assays: a high uniform concentration of an odour will block chemotaxis toward a point source of that odour but not toward point sources of other odours $^{1,6}$. The five odours sensed by the two AWC neuronsbutanone, benzaldehyde, 2,3-pentanedione, isoamyl alcohol and 2,4,5-trimethylthiazole-use a common cyclic GMP signalling pathway, comprising the $\mathrm{G}_{\alpha}$ subunit ODR-3, the transmembrane guanylyl cyclases ODR-1 and DAF-11, and the cyclic-nucleotidegated channel TAX-2/TAX-4 (refs 1,6-10). Overexpression of ODR-1 perturbs discrimination between butanone and benzaldehyde through mechanisms that are not understood ${ }^{6}$.

To gain insight into the mechanism of discrimination, we performed a genetic screen for loss-of-function mutants that cannot detect a point source of benzaldehyde in a high uniform concentration of butanone (Fig. 1a; and Methods). The most striking defect was observed in the mutant $k y 542$, which exhibited a complete loss of benzaldehyde chemotaxis in the presence of a

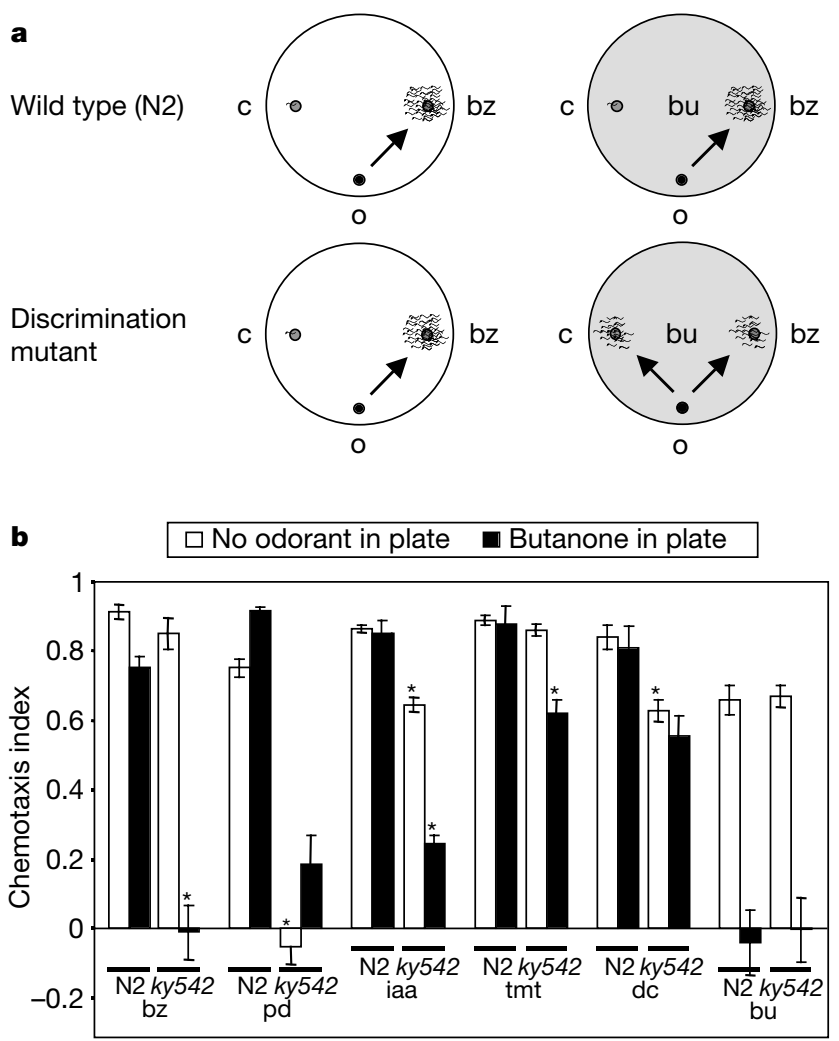

Figure 1 The ky542 mutant has defects in olfaction and olfactory discrimination. a. Animals are scored for chemotaxis to a point source of benzaldehyde (bz) in the absence (chemotaxis assay, left) or presence (discrimination assay, right) of a uniform field of butanone (bu). Discrimination mutants fail to chemotax to benzaldehyde in the presence of butanone. c, control; o, origin. b. Population chemotaxis assays in the absence (open bars) or presence (filled bars) of butanone. Asterisks indicate statistically significant $(P<0.001)$ defects in ky542 mutants. Genotypes and odorants are listed below each assay. N2, wild type; bu, 1:1,000 butanone; bz, 1:200 benzaldehyde; dc, 1:1,000 diacetyl; iaa, 1:100 isoamyl alcohol; pd, 1:10,000 2,3pentanedione; tmt, 1:1,000 2,4,5-trimethylthiazole. The abbreviations are the same for all figures. 


\section{The zebrafish Nodal signal Squint functions as a morphogen}

\section{Yu Chen \& Alexander F. Schier}

Developmental Genetics Program, Skirball Institute of Biomolecular Medicine, and Department of Cell Biology, New York University School of Medicine, New York, New York 10016, USA

Secreted morphogens induce distinct cellular responses in a concentration-dependent manner and act directly at a distance ${ }^{1-7}$. The existence of morphogens during mesoderm induction and patterning in vertebrates has been highly controversial, and it remains unknown whether endogenous mesoderm inducers act directly as morphogens ${ }^{8-10}$, function locally ${ }^{9}$ or act through relay mechanisms ${ }^{11-12}$. Here we test the morphogen properties of Cyclops and Squint-two Nodal-related transforming growth factor- $\beta$ signals required for mesoderm formation and patterning in zebrafish ${ }^{13-16}$. Whereas different levels of both Squint and Cyclops can induce different downstream genes ${ }^{14,17-19}$, we find that only Squint can function directly at a distance. These results indicate that Squint acts as a secreted morphogen that does not require a relay mechanism.

The level of Nodal signalling is a key factor in determining the cell fate induced in responding cells ${ }^{14,17-21}$. We first tested whether Cyclops (Cyc) and Squint (Sqt) can act on responding cells at a distance, and whether the activation of different downstream genes is dependent on concentration and distance. To provide a local source of Sqt or Cyc, sqt or $c y c$ RNA was injected, together with the lineage tracer fluorescein-dextran, into a single cell of 128-256-cell zebrafish (Danio rerio) embryos (Fig. 1a). The injected embryos were fixed $3 \mathrm{~h}$ later before the onset of gastrulation ( $50 \%$ epiboly), and analysed by in situ RNA hybridization with antisense probes for no tail/Brachyury ( $n t l)$, goosecoid ( $g s c)$, bhikhari (bik) and floating head $(f l h)$ - known targets of Nodal signalling ${ }^{13,18,22-23}$.

We found that $f l h, n t l$ and bik were expressed by cells $4-6(f l h)$ and 6-8 ( $n t l$, bik) cell diameters away from Sqt-producing cells (Fig. 1c, $\mathrm{e}, \mathrm{m})$. In contrast, $g s c$ was detected only in cells expressing sqt and their immediate neighbours (Fig. 1d). This pattern recapitulates the expression of these genes in the zebrafish organizer, where high levels of Nodal signalling are required to activate $g s c$, and lower levels are sufficient to induce expression of $f l h, n t l$ and $b i k^{18}$. When we reduced the levels of $s q t$ tenfold, $n t l$ was induced only close to the source and $g s c$ was not induced (Fig. 1f, g). Expression of different levels of $c y c$ resulted in a similar concentration-dependent induction of $n t l$ and $g s c$. High levels induce the expression of both genes, whereas lower levels induce only $n t l$ (Fig. 1i, j; and data not shown); unexpectedly, however, we never observed $n t l$ or bik expression beyond two cell diameters from $c y c$-expressing cells, although the level of $c y c$ was high enough to induce $g s c$ expression (Fig. 1i, j, l).

Notably, increasing the injected $c y c$ RNA to 60 pg did not change the ectopic $n t l$ domain, but induced ectopic gsc expression in all cells injected with RNA (data not shown). This indicates that more active Cyc protein is made, although western analysis with a haemagglutinin A (HA)-tagged form of Cyc revealed no significant difference in HA-Cyc protein production on injection of $6 \mathrm{pg}$ or $60 \mathrm{pg}$ (data not shown). This result indicates that post-transcriptional mechanisms such as translational efficiency or protein stability might contribute to the range of action of $c y c$.

The expression of bik in $c y c$, sqt and $c y c ; s q t$ double mutants is consistent with different ranges for endogenous Cyc and Sqt (Fig. 1o-s). In cyc mutants, Sqt is sufficient to activate bik 6-8 cells from the margin (Fig. 1q), whereas in sqt mutants, Cyc induces bik only locally (Fig. 1p). The amino-terminal prodomain of transforming growth factor (TGF) $\beta$ signals is thought to interact with extracellular matrix and so may be responsible for the different range of action of Cyc and $\mathrm{Sqt}^{9,24}$. We found, however, that the prodomains do not change the range of chimaeric Cyc-Sqt and Sqt-Cyc proteins (Fig. 1h, k), indicating that differences in the

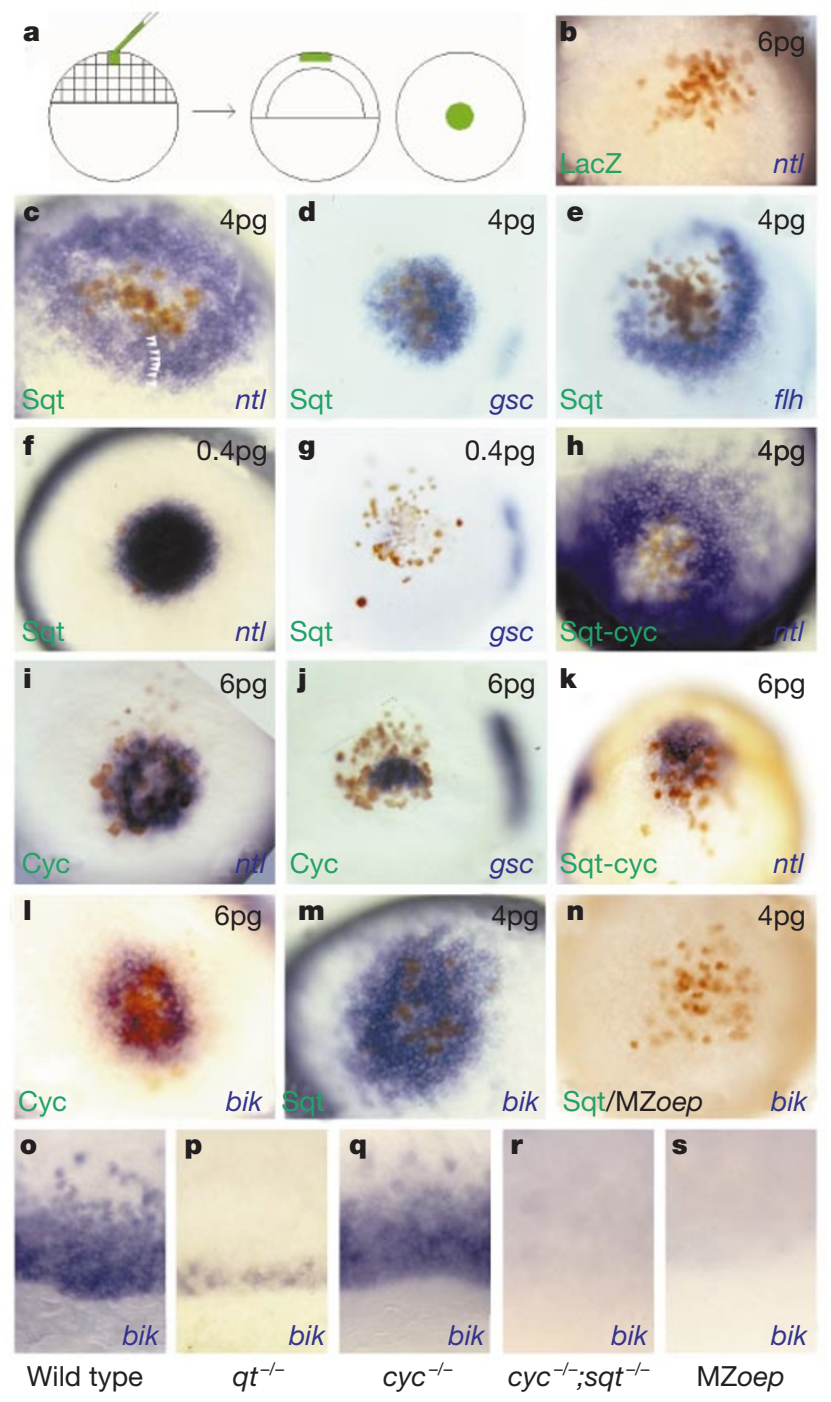

Figure 1 Squint has long-range effects, whereas Cyclops has short-range effects. a, Single-cell injection; RNAs are co-injected with fluorescein-dextran (green) into wildtype embryos at the 128-256-cell stage; embryos are fixed $3 \mathrm{~h}$ later at 50\% epiboly (left, lateral view; right, animal pole view). $n t l, g s c$, flh and bikexpression is examined by wholemount RNA in situ hybridization (blue stain); injected cells are stained brown by an antifluorescein antibody. $\mathbf{b}-\mathbf{n}$, Single-cell injections of RNA; all images are animal pole views. b, $6 \mathrm{pg}$ of lacZ mRNA; no ectopic ntl expression is observed ( $n=12 / 12)$. c-e, 4 pg of sqt RNA; $n t /(\mathbf{c}, n=27 / 27)$ and $f / h(\mathbf{e}, n=18 / 18)$ are expressed in a wider domain than $g s c$ (d, $n=34 / 35)$; arrowheads in c indicate the domain of ectopic $n t /$ expression, about eight cell diameters from sqt-expressing cells (about $100 \mu \mathrm{m}$ ). $\mathbf{f}, \mathbf{g}, 0.4 \mathrm{pg}$ of sqt RNA; the ectopic $n t /$ domain almost overlaps with the Sqt-producing cells (f, $n=14 / 15)$; no ectopic gsc expression is induced ( $\mathbf{g}, n=13 / 14)$. h, 4 pg of $c y c-s q t \operatorname{RNA}(n=22 / 22)$; the ectopic $n t /$ domain is similar to that induced by $\operatorname{sqtRNA}(\mathbf{c})$. i, j and I, 6 pg of $c y c$ RNA; the ectopic $n t$ and bik domains almost overlap with the Cyc-producing cells (i, $n=18 / 20 ; \mathbf{I}, n=11$ / 11) even though the level of Cyc is high enough to induce ectopic $g s c(\mathbf{j}, n=16 / 18)$. k, $6 \mathrm{pg}$ of $s q t-c y c$ RNA; the ectopic $n t /$ domain is similar to that induced by cyc RNA injection ( $n=21 / 22)$. $\mathbf{m}, \mathbf{n}, 4$ pg of sqt RNA in wild-type $(\mathbf{m})$ and MZoep (n) embryos; ectopic bik expression is induced up to eight cells away from the Sqt-producing cells in wild type ( $\mathbf{m}, n=20 / 20$ ), but no ectopic bik expression is induced in MZoep embryo (n, $n$ $=14 / 14)$. o-s, bik expression at the blastoderm margin at 50\% epiboly in different genetic backgrounds, lateral views; bik expression is dependent on Nodal signalling around the entire margin. 


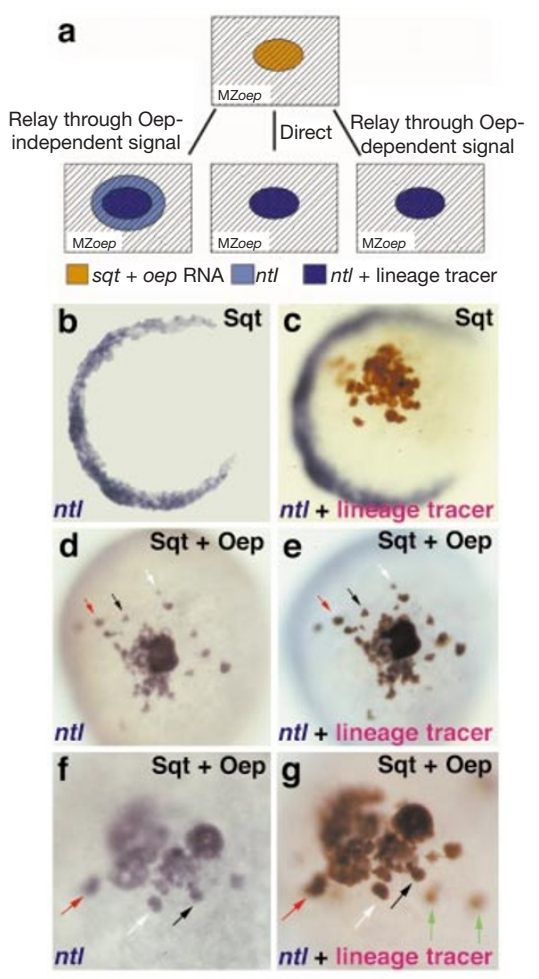

Figure 2 Squint signals to distant cells either directly or through an Oep-dependent relay signal. a, Design and predictions for the experiment described in $\mathbf{b}-\mathbf{g}$. b-g, Single-cell injection into MZoep embryo of $4 \mathrm{pg}$ of sqtRNA (b, c) or $4 \mathrm{pg}$ of sqtRNA plus $4 \mathrm{pg}$ of oep RNA (d-g). Note that MZoep mutants express $n t /$ at the lateral and ventral margin, but not dorsally (b, c); b, d, f are in situ stainings of $n t l$ expression (blue); $\mathbf{c}, \mathbf{e}, \mathbf{g}$ are double stainings of both $n t /$ expression (blue) and lineage tracer detected with anti-fluorescein antibody (brown). b, c, No ectopic ntl expression (blue) is detected owing to the inability of MZoep cells to respond to Sqt $(n=14 / 14)$. $\mathbf{d}-\mathbf{g}$, $n t /$ is only expressed by cells injected with sqt and oep RNA ( $n=19 / 19)$. Arrows of different colours indicate the corresponding cells in $\mathbf{d}$ and $\mathbf{e}$, as well as in $\mathbf{f}$ and $\mathbf{g}$; note that there are two cells marked by the green arrows in $\mathbf{g}$ that contain the lineage tracer but do not express $n t$.

mature region contribute to the different ranges of action. Together, these results indicate different effective ranges for Sqt and Cyc.

Given the dynamic cell movements during early embryogenesis, the apparent long-range effect of Sqt might be a result of the displacement of cells that initiated expression of $n t l$ because early on they were adjacent to $s q t$-expressing cells ${ }^{25}$. Although the shortrange effect of Cyc argues against this possibility, we tested it by transplanting labelled wild-type cells at a distance from the sqtexpressing cells. To make sure that these two cell populations never got within close proximity of each other, we monitored their relative positions after transplantation. We found that transplanted cells that maintained their distance from the Sqt source expressed $n t l$, as did their neighbouring host cells (Supplementary Information Fig. 1). Thus, cell movement does not cause the long-range effect of Sqt.

Two models can explain the long-range effect of Sqt: Sqt might act as a morphogen and directly activate target gene expression at a distance; or Sqt might activate a relay signal, which then acts on distant cells. Both mechanisms have been invoked previously to account for the long-range effects of non-endogenous TGF- $\beta$ signals ${ }^{8-12}$. To assay the range of Sqt's direct action, we made use of the observation that cells that lack the activity of the EGF-CFC protein One-eyed pinhead (Oep) cannot perceive Nodal signals ${ }^{22}$. Oep is an extracellular cofactor required cell-autonomously for the reception of Nodal signals ${ }^{22,26-28}$.

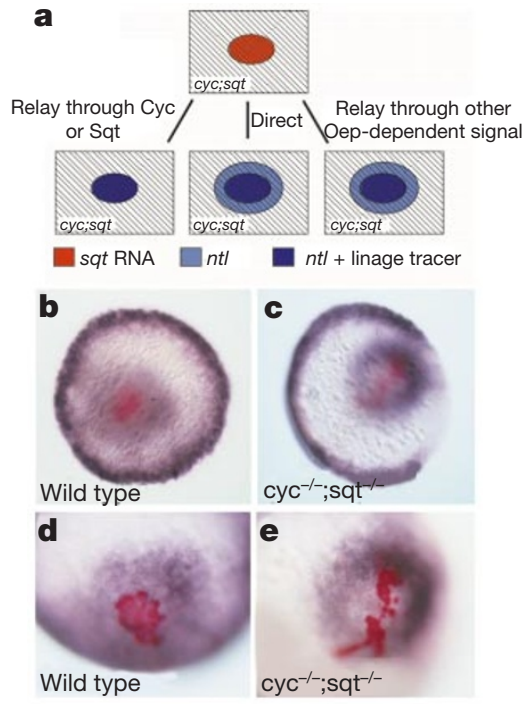

Figure 3 The long-range effect of Sqt does not depend on the induction of the endogenous cyc or sqt genes. a, Design and predictions for the experiments shown in b-e. b-e, Single-cell injection of $4 \mathrm{pg}$ of sqt RNA plus lineage tracers biotin-dextran and rhodamine-dextran into wild-type (b, d, $n=18 / 18)$ and cyc;sqt double mutant embryos (c, e, $n=12 / 12$ ) at the 128-256-cell stage. b, c, Focus is on the expression domain of $n t /$ in marginal cells; cyc;sqt double mutants were distinguished from sibling embryos (b) by the lack of $n t$ le expression on the dorsal side (c). d, e, High-magnification views of the embryos in $\mathbf{b}$ and $\mathbf{c}$; the lineage tracer biotin-dextran was detected with the $\mathrm{ABC}$ kit from Vectastain (red).

Maternal-zygotic mutants for oep (MZoep embryos) have an identical phenotype to $c y c$;sqt double mutants and are unresponsive to Nodal signals ${ }^{22}$. These mutants are not impaired in signalling for fibroblast growth factor (FGF), bone morphogenetic protein (BMP) or Activin $^{22}$, but none of the known Nodal-responsive genes (bik, $n t l, g s c$, flh, antivin, pitx2, cyc) can be activated by overexpression of Sqt in MZoep mutants, and ubiquitous or local expression of Sqt has no phenotypic effects in MZoep mutants ${ }^{22}$ (Figs 1n, 2c; and data not shown). Using these MZoep mutants, we tested whether Sqt acts directly at a distance or indirectly through a relay signal.

We first juxtaposed Sqt-responsive cells with Sqt non-responsive cells (oep mutant) to test whether an Oep-independent relay signal such as $\mathrm{FGF}^{12}$ is involved in the long-range effect of Sqt (Fig. 2). We injected both sqt and oep RNAs into a single cell of 128-256-cell MZoep embryos. oep RNA injection allows the injected cells to transduce the Sqt signal. If Sqt can induce a relay signal whose transduction is Oep independent and activates target genes such as $n t l$, then $n t l$ would be expressed not only in the injected cells but also in the surrounding oep mutant cells (Fig. 2a). But if Sqt acts as a morphogen or relays through signals whose transduction is dependent on Oep, then $n t l$ expression would be observed only in cells expressing Oep. Consistent with the second scheme, we found that only cells containing both Oep and Sqt expressed $n t l$ (Fig. $2 \mathrm{~d}-\mathrm{g}$ ). No non-autonomous induction of $n t l$ was observed.

To test whether the long-range effect of Sqt is a result of propagated induction of $c y c$ or $s q t$, we analysed $n t l$ expression induced by Sqt in cyc;sqt double-mutant embryos (Fig. 3a). We found that the domain of $n t l$ expression induced in these embryos (Fig. 3c, e) is very similar to that in wild-type embryos (Fig. 3b, d), suggesting that the long-range effect of Sqt does not depend on the induction of the endogenous $c y c$ or sqt genes.

These results are consistent with the idea that Sqt acts as a morphogen, but it is also possible that Sqt may relay through an unknown signal whose transmission is Oep dependent (Fig. 4a). To address this possibility, we injected sqt RNA into a single cell of 


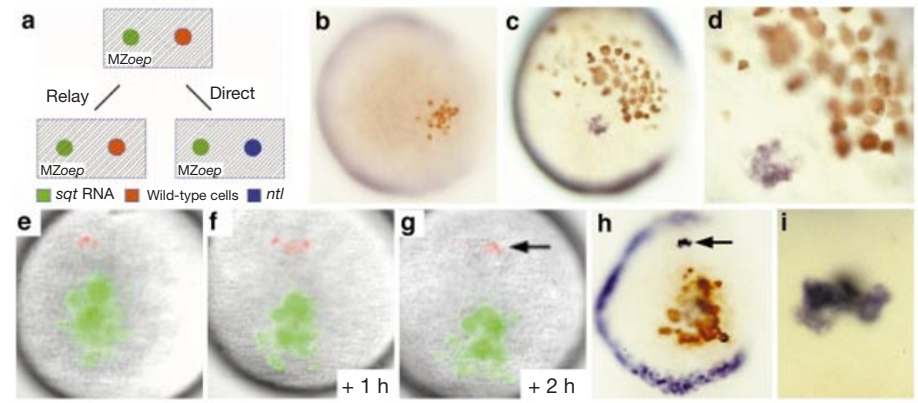

Figure 4 Squint signals directly to distant cells. a, Experimental design and predictions. b. Control; transplantation of wild-type cells (brown) into MZoep embryo, no ectopic nt/ expression is observed $(n=14 / 14)$. Note that MZoep mutants express $n t l$ at the lateral and ventral margin, but not dorsally. c-i, Single-cell injection of $4 \mathrm{pg}$ of $s q t$ RNA and fluorescein-dextran (green) into MZoep embryo, followed by transplanting wild-type donor cells labelled with biotin-dextran and rhodamine-dextran (red) at a distance to the sqt- injected cells (green) at the 1,000-2,000-cell stage; two examples (c-d and $\mathbf{e}-\mathbf{i}$ ) are shown. $\mathbf{c}, \mathbf{d}$, Note ectopic $n t /$ staining (blue) at a distance from the sqt-expressing cells (brown) ( $n=7 / 18)$. $\mathbf{e}-\mathbf{g}$, Images of the embryo in $\mathbf{h}$ and $\mathbf{i}$ after transplantation; $\mathbf{e}$ was taken shortly after transplantation; $\mathbf{f}$ and $\mathbf{g}$ were taken $1 \mathrm{~h}(\mathbf{f})$ and $2 \mathrm{~h}(\mathbf{g})$ after $\mathbf{e}$.

$\mathbf{h}, \mathbf{i}$, Transplanted cells (arrow in $\mathbf{g}$ ) stained with $n t /$ probe (arrow); i, High-magnification view of the $n t$-expressing cells in $\mathbf{h}(n=6 / 12)$.
MZoep mutants and then transplanted several wild-type cells at a distance to the sqt-expressing cells. We also followed the movement of both sqt-expressing mutant cells and transplanted wild-type cells to ensure that they were not in close proximity between the time of transplantation and fixation (Fig. $4 \mathrm{e}-\mathrm{g}$ ).

Owing to the lack of Oep function in sqt-expressing and neighbouring cells, Sqt cannot activate the Nodal signalling pathway in these cells and thus no relay signal can be produced. If Sqt acts by a relay mechanism, the transplanted wild-type cells would not be able to express $n t l$. But if Sqt activates gene expression directly at a distance, wild-type cells should be able to receive the Sqt signal and express $n t l$. Consistent with the latter possibility, we found that wild-type cells in MZoep mutant embryos can express $n t l$ in response to a distant source of Sqt. This result suggests that Sqt activity produced in unresponsive (oep mutant) cells can traverse a field of unresponsive (oep mutant) cells to elicit an effect in distant responsive (wild-type) cells. These results show that the long-range effect of Sqt is direct, requiring no relay signal (Fig. 4c-i).

The idea of locally secreted signals that act as morphogens and directly pattern a tissue by eliciting distant responses has been an attractive mechanism to explain many developmental events ${ }^{1-10}$. The potential of vertebrate mesoderm inducers to act as morphogens has been debated for a long time. Seemingly contradictory analyses of non-endogenous TGF- $\beta$ signals have supported conflicting models. Elegant studies in Xenopus explants have revealed the potential of Activin to act as a long-range morphogen ${ }^{8-10}$. In contrast, in vivo studies in zebrafish have suggested that Activin acts only locally and induces FGF as a relay signal ${ }^{12}$. Similarly, Xnr2 and TGF- $\beta 1$ have been suggested to act only at short range ${ }^{9,11}$. Our studies using the in vivo mesoderm inducers Cyc and Sqt now indicate that both short- and long-range mechanisms can operate during mesoderm induction and patterning. Notably, our results indicate that Sqt may act as a secreted morphogen: first, different levels of Sqt induce different downstream responses in a concentration- and distance-dependent way ${ }^{14,17-19}$ (Fig. 1); second, Sqt can act directly at a distance (Figs 2-4). These results indicate that Squint acts as a secreted morphogen that does not require a relay mechanism.

\section{Methods}

\section{Single-cell injection}

The lineage tracer fluorescein-dextran was co-injected with the RNA to mark the injected cell and its progeny. We synthesized $s q t, c y c$ and oep sense, capped mRNAs as described ${ }^{18}$. RNA in situ hybridization and anti-fluorescein antibody staining were performed as described $^{22}$.

\section{Genotyping}

After photography, embryos were washed twice in benzyl benzoate : benzyl alcohol (2:1), two or three times in $100 \%$ methanol and once in $100 \%$ ethanol. We extracted genomic DNA using the DNeasy Tissue Kit (Qiagen). After extraction, genomic DNA was precipitated and resuspended in $50 \mu \mathrm{H} \mathrm{H}_{2} \mathrm{O}$. Five microlitres of the genomic DNA was used as a template in each polymerase chain reaction (PCR). Primers and conditions for genotyping $s q t^{c z 35}$ and $c y c^{m 294}$ have been described ${ }^{13}$.

\section{Chimaera construction}

Cyc-Sqt and Sqt-Cyc fusion proteins were constructed using PCR amplification. The junction sequence of Cyc-Sqt is RRGRRNHRT, in which the underlined sequence is the C terminus of the Cyc prodomain and the rest is the $\mathrm{N}$ terminus of the Sqt mature peptide. The junction sequence for Sqt-Cyc is RRHRRGPPVRR, in which the underlined sequence is the $\mathrm{N}$ terminus of the Cyc mature peptide and the rest is the $\mathrm{C}$ terminus of the Sqt prodomain.

\section{Transplantation and triple labelling}

Donor embryos were injected with biotin-dextran and rhodamine-dextran at the 1-4-cell stage. We carried out transplantation as described ${ }^{22}$. After in situ hybridization and detection of fluorescein-dextran, the biotin-dextran labelled donor cells were detected with the alkaline phosphatase substrate kit 1 (Vector Laboratories, Inc.).

\section{Imaging}

Fluorescent and Nomarski images were taken after mounting the embryo in $2.5 \%$ methyl cellulose. Images were acquired as described ${ }^{18}$.

\section{Received 18 October 2000; accepted 26 February 200}

1. Turing, A. M. The chemical basis of morphogenesis. Phil. Trans. R. Soc. Lond. B. 237, 37-72 (1952).

2. Wolpert, L. Positional information and the spatial pattern of cellular differentiation. J. Theor. Biol. 25, 1-47 (1969).

3. Nellen, D., Burke, R., Struhl, G. \& Basler, K. Direct and long-range action of a DPP morphogen gradient. Cell 85, 357-368 (1996).

4. Lecuit, T. et al. Two distinct mechanisms for long-range patterning by Decapentaplegic in the Drosophila wing. Nature 381, 387-393 (1996).

5. Zecca, M., Basler, K. \& Struhl, G. Direct and long-range action of a wingless morphogen gradient. Cell 87, 833-844 (1996).

6. Neumann, C. J. \& Cohen, S. M. Long-range action of Wingless organizes the dorsal-ventral axis of the Drosophila wing. Development 124, 871-880 (1997).

7. Neumann, C. \& Cohen, S. Morphogens and pattern formation. BioEssays 19, 721-729 (1997).

8. Gurdon, J. B., Harger, P., Mitchell A. \& Lemaire, P. Activin signalling and response to a morphogen gradient. Nature 371, 487-492 (1994).

9. Jones, C. M., Armes, N. \& Smith, J. C. Signalling by TGF- $\beta$ family members: short-range effects of Xnr-2 and BMP-4 contrast with the long-range effects of activin. Curr. Biol. 6, 1468-1475 (1996).

10. McDowell, N., Zorn, A. M., Crease, D. J. \& Gurdon, J. B. Activin has direct long-range signalling activity and can form a concentration gradient by diffusion. Curr. Biol. 7, 671-681 (1997).

11. Reilly, K. M. \& Melton, D. A. Short-range signaling by candidate morphogens of the TGF beta family and evidence for a relay mechanism of induction. Cell 86, 743-754 (1996)

12. Rodaway, A. et al. Induction of the mesendoderm in the zebrafish germ ring by yolk cell-derived TGF$\beta$ family signals and discrimination of mesoderm and endoderm by FGF. Development 126, 30673078 (1999).

13. Feldman, B. et al. Zebrafish organizer development and germ-layer formation require nodal-related signals. Nature 395, 181-185 (1998).

14. Sampath, K. et al. Induction of the zebrafish ventral brain and floorplate requires cyclops/nodal signalling. Nature 395, 185-189 (1998). 
15. Rebagliati, M. R., Toyama, R., Haffter, P. \& Dawid, I. B. cyclops encodes a nodal-related factor involved in midline signaling. Proc. Natl Acad. Sci. USA 95, 9932-7 (1998).

16. Schier, A. F. \& Shen, M. M. Nodal signalling in vertebrate development. Nature 403, 385-389 (2000).

17. Erter, C. E., Solnica-Krezel, L. \& Wright, C. V. Zebrafish nodal-related 2 encodes an early mesendodermal inducer signaling from the extraembryonic yolk syncytial layer. Dev. Biol. 204, $361-$ $372(1998)$

18. Gritsman, K., Talbot, W. S. \& Schier, A. F. Nodal signaling patterns the organizer. Development 127, 921-932 (2000)

19. Thisse, B., Wright, C. V. \& Thisse, C. Activin- and Nodal-related factors control antero-posterior patterning of the zebrafish embryo. Nature 403, 425-428 (2000).

20. Jones, C. M., Kuehn, M. R., Hogan, B. L., Smith, J. C. \& Wright, C. V. Nodal-related signals induce axial mesoderm and dorsalize mesoderm during gastrulation. Development 121, 3651-3662 (1995).

21. Agius, E., Oelgeschlager, M., Wessely, O., Kemp, C. \& De Robertis, E. M. Endodermal Nodal-related signals and mesoderm induction in Xenopus. Development 127, 1173-1183 (2000).

22. Gritsman, K. et al. The EGF-CFC protein one-eyed pinhead is essential for nodal signaling. Cell 97, 121-132 (1999).

23. Vogel, A. M. \& Gerster, T. Promoter activity of the zebrafish bhikhari retroelement requires an intact activin signaling pathway. Mech. Dev. 85, 133-146 (1999).

24. Ruppert, R., Hoffmann, E. \& Sebald, W. Human bone morphogenetic protein 2 contains a heparinbinding site which modifies its biological activity. Eur. J. Biochem. 237, 295-302 (1996).

25. Pfeiffer, S., Alexandre, C., Calleja, M. \& Vincent, J. P. The progeny of wingless-expressing cells deliver the signal at a distance in Drosophila embryos. Curr. Biol. 10, 321-324 (2000).

26. Schier, A. F., Neuhauss, S. C., Helde, K, A., Talbot, W. S. \& Driever, W. The one-eyed pinhead gene functions in mesoderm and endoderm formation in zebrafish and interacts with no tail. Development 124, 327-342 (1997)

27. Zhang, J., Talbot, W. S. \& Schier, A. F. Positional cloning identifies zebrafish one-eyed pinhead as a permissive EGF-related ligand required during gastrulation. Cell 92, 241-251 (1998).

28. Strähle, U. et al. one-eyed pinhead is required for development of the ventral midline of the zebrafish (Danio rerio) neural tube. Genes Funct. 1, 131-148 (1997).

Supplementary information is available on Nature's World-Wide Web site (http://www.nature.com) or as paper copy from the London editorial office of Nature

\section{Acknowledgements}

We thank members of the Schier and Yelon laboratories for discussions; R. Burdine, A. Carmany-Rampey, K. Joubin, R. Lehmann, G. Struhl, W. Talbot and D. Yelon for comments on the manuscript; S. Zimmerman, R. Feeney and T. Bruno for fish care. Y.C. is the Rebecca Ridley Kry Fellow of the Cancer Research Fund of the Damon Runyon-Walter Winchell Foundation. A.F.S. is a Scholar of the McKnight Endowment Fund for Neuroscience and the Irma T. Hirschl Trust, and is supported by grants from the NIH.

Correspondence and requests for materials should be addressed to A.F.S (e-mail: schier@saturn.med.nyu.edu).

\section{MOR1 is essential for organizing cortical microtubules in plants}

Angela T. Whittington, Oliver Vugrek, Ke Jun Wei, Nortrud G. Hasenbein, Keiko Sugimoto*, Madeleine C. Rashbrooke \& Geoffrey 0. Wasteneys

Plant Cell Biology Group, Research School of Biological Sciences, The Australian National University, GPO Box 475, Canberra, ACT 2601, Australia

Microtubules orchestrate cell division and morphogenesis, but how they disassemble and reappear at different subcellular locations is unknown. Microtubule organizing centres are thought to have an important role, but in higher plants microtubules assemble in ordered configurations even though microtubule organizing centres are inconspicuous or absent. Plant cells generate highly organized microtubule arrays that coordinate mitosis, cytokinesis and expansion. Inhibiting microtubule assembly prevents chromosome separation ${ }^{1}$, blocks cell division ${ }^{2}$ and impairs growth polarity ${ }^{3}$. Microtubules are essential for the formation of cell walls, through an array of plasma-membrane-associated cortical microtubules whose control mechanisms are unknown. Using a genetic strategy to identify microtubule organizing factors in Arabidopsis thaliana, we isolated temperature-sensitive

Present address: John Innes Centre, Department of Cell and Developmental Biology, Norwich NR4 7UH, UK. mutant alleles of the MICROTUBULE ORGANIZATION 1 (MOR1) gene. Here we show that MOR1 is the plant version of an ancient family of microtubule-associated proteins ${ }^{4}$. Point mutations that substitute single amino-acid residues in an amino-terminal HEAT repeat impart reversible temperaturedependent cortical microtubule disruption, showing that MOR1 is essential for cortical microtubule organization.

In most plant cells that display diffuse rather than tip growth, microtubules localize to the cortical cytoplasm perpendicular to the major axis of expansion. Microtubules and cellulose microfibrils often have similar orientation patterns in elongating cells ${ }^{5}$ and it is generally accepted, but not proven, that cortical microtubules control the alignment of cellulose microfibrils ${ }^{6}$. Identifying the factors that organize microtubule arrays at the periphery of plant cells is a necessary step towards understanding the mechanisms that underlie wall deposition and, hence, plant morphogenesis.

To identify factors regulating cortical microtubule organization in plant cells, we used immunofluorescence microscopy to screen chemically mutagenized seedlings of $A$. thaliana for aberrant microtubule patterns. One mutant locus, morl, causes temperature-sensitive cortical microtubule shortening and disorganization (Fig. 1) and consequent morphological defects. We used ecotypespecific markers to identify MOR1 as a gene of around 14 kilobases $(\mathrm{kb})$ that encodes a protein with a predicted relative molecular mass of 217,000 $\left(M_{\mathrm{r}} 217 \mathrm{~K}\right)$ (Fig. 2a) that has significant deduced aminoacid sequence similarity to human $\mathrm{TOGp}^{7}$, Xenopus MAP215
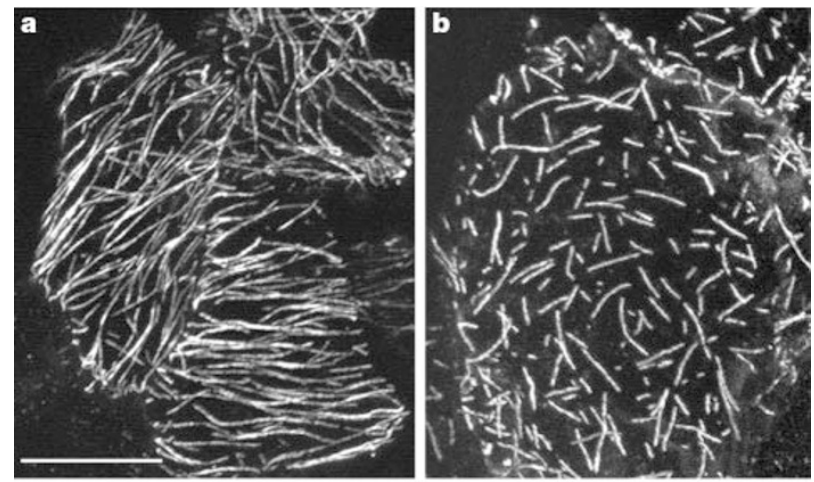

Figure 1 Mutations in the MOR1 gene cause temperature-dependent microtubule disruption. We used anti-tubulin immunofluorescence to label cortical microtubules in epidermal cells of the first true leaf of 21-day-old seedlings after incubating seedlings at $29^{\circ} \mathrm{C}$ for $2 \mathrm{~h}$ before fixation. a, Wild type. b, mor1-1 homozygote. Scale bar, $25 \mu \mathrm{m}$.

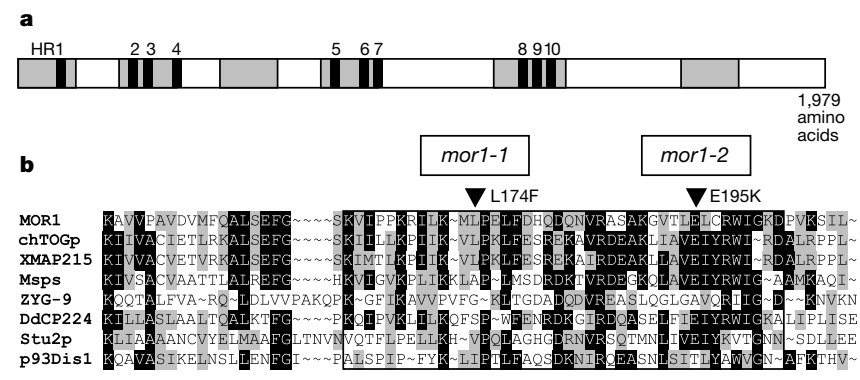

Figure 2 MOR1 protein structure. a, Schematic representation with shaded boxes indicating conserved domains between MOR1, TOGp, XMAP215, MSPS and DdCP224 The shorter ZYG-9 and yeast proteins share the first five and first four regions of homology, respectively. Black stripes show putative HEAT repeats $(\mathrm{HR})$ in relation to these conserved domains. b. Deduced amino-acid sequence comparison of MOR1's HEAT repeat-1 with equivalent repeats in homologues. Black-shaded residues indicate identity, grey-shaded residues indicate similarity (40\% threshold), outlined box indicates HEAT repeat. Mutations altering MOR1 amino-acid residues are indicated by arrowheads. 